\title{
Allometric equations for predicting mineralomass in high-forest chestnut stands in Portugal
}

\author{
M.S. Patrício1,a and M. Tomé ${ }^{2}$ \\ ${ }^{1}$ Departamento de Ambiente e Recursos Naturais, Instituto Politécnico de Bragança, ESA-CIMO. Campus de Sta \\ Apolónia, 5300-253 Bragança, Portugal; ${ }^{2}$ Centro de Estudos Florestais, Instituto Superior de Agronomia, \\ Universidade de Lisboa, Tapada da Ajuda, 1349-017 Lisboa, Portugal.
}

\begin{abstract}
The assessment of nutrients in biomass tree-components is a time-consuming and expensive process, often involving tree felling, not always possible or desirable. Thus, mineralomass prediction equations are an important tool for the quantification of the nutrients exported in management and harvesting activities towards its replacement and sustainable management, as well as to evaluate the effect of other disturbances in the balance of ecosystems. Thus, given the importance of the relationship of biomass and nutrients (mineralomass) for dynamic and sustainable management of chestnut woodlands, above-ground mineralomass was studied in sweet chestnut (Castanea sativa Mill.) high-forest stands located in northern Portugal. Nutrient-specific prediction equations that allow estimating the mineralomass $(\mathrm{N}, \mathrm{P}$, $\mathrm{K}, \mathrm{Ca}, \mathrm{Mg}, \mathrm{S}, \mathrm{B}$ and $\mathrm{C}$ ) stocked in the trees above the ground, considering the tree as a whole (stem + bark + branches + leaves + flowers) and seperately for each tree component: stem-wood, stem-bark, branches, leaves and flowers, based on tree dendrometric variables, DBH (diameter breast height) and total height, were developed.. Linear and non-linear regression estimation methods were used. Data analysis was based on information collected in destructive analysis of 34 felled trees, distributed by the existing diameter classes $(10-65 \mathrm{~cm})$ in three adult chestnut stands. Several linear and nonlinear equations were fitted by the least squares method to select models. A simultaneous fit by SUR method using iterative seemingly unrelated regression (ITSUR) was used for the final selected models. The best-fitting models are presented.
\end{abstract}

Keywords: Castanea sativa Mill., allometric models, above-ground tree mineralomass, silviculture, forest management

\section{INTRODUCTION}

Land-use management, as forest tending and harvesting, can have a strong impact on nutrient cycling and ecosystem sustainability. The knowledge of the distribution of nutrients in the different sections making up the above-ground biomass is of great importance for making realistic predictions about the export of nutrients under different forest management systems (Augusto et al., 2000). The information of the content of mineral elements in the tree-component biomass is essential to understand their status and flow in the whole system, as well as to assess the productive capacity of ecosystems and management implications for forest sustainability. However, the evaluation of biomass and nutrients in tree-components is a time-consuming and expensive process, often involving tree felling, not always possible or desirable. Moreover, laboratory analyses are costly and time-consuming.

Nowadays, the use of allometric equations for the prediction of tree biomass is quite common. These equations, when available for a given species, allow the estimation of total biomass or tree-component biomass using dendrometric variables easier to measure, such as diameter at breast height (DBH) and total height. One of the methods to estimate the

a'E-mail: sampat@ipb.pt 
quantity of a mineral in the biomass (mineralomass) is to multiply the estimated biomass by these allometric equations by the concentration of the respective mineral element obtained through laboratory analysis. However, the concentration of minerals in tree-biomass components for a given species varies considerably between sites and it is not always available in the literature. So, it is essential to provide tools to estimate directly the amount of minerals stored on the tree-component biomass because the concentration of the minerals in itself does not present an acceptable functional relationship with dendrometric variables of the tree.

Thus, given the importance of the relationship of biomass and nutrients for dynamic and sustainable management of chestnut woodlands, above-ground mineralomass was studied in sweet chestnut (Castanea sativa Mill.) high-forest stands located in northern Portugal. The aim of this study is to provide allometric equations for chestnut high-forest woodlands for estimating the mineralomass using the dendrometric variables DBH and total height $(h)$ of the tree. These nutrient-specific prediction equations will allow estimating the mineralomass ( $\mathrm{N}, \mathrm{P}, \mathrm{K}, \mathrm{Ca}, \mathrm{Mg}, \mathrm{S}, \mathrm{B}$ and $\mathrm{C}$ ) stocked in the trees above the ground, considering the tree as a whole (stem + bark + branches + leaves + flowers) and seperately for each tree component: stem-wood, stem-bark, branches, leaves and flowers, based on tree dendrometric variables ( $\mathrm{DBH}, \mathrm{h}$ ) to be applied to the sustainable management of sweet chestnut high-forest stands..

\section{MATERIALS AND METHODS}

\section{General characteristics of the sites}

This study was based on biomass information collected in the three mature chestnut high-forest stands located in three mountains of northern Portugal: Bornes $\left(41^{\circ} 29^{\prime} 42^{\prime \prime} \mathrm{N}\right.$, $6^{\circ} 55^{\prime} 12^{\prime \prime} \mathrm{W}$ and $800 \mathrm{~m}$ a.s.l.), Marão (41.14'46” N, $7^{\circ} 55^{\prime} 04^{\prime \prime} \mathrm{W}$ and $900 \mathrm{~m}$ a.s.l.) and Padrela $\left(41^{\circ} 31^{\prime} 47^{\prime \prime} \mathrm{N}, 7^{\circ} 35^{\prime} 22^{\prime \prime} \mathrm{W}\right.$ and $850 \mathrm{~m}$ a.s.l.) which have been monitored over time. Sampling followed a west-to-east transect across to northern Portugal from a more-Atlantic-to-lessmaritime influence. General characteristics of these sites can be found in Patrício et al. $(2009,2012,2014)$.

\section{Field data}

In order to obtain biomass data, 34 trees were felled according to the existent diameter classes. The methodology of biomass collection was described in Patrício et al. (2005). These samples of tree-biomass components were analyzed to determine their mineral concentrations.

\section{Treatment of the samples in laboratory}

The collected biomass samples of leaves, flowers and barks were dried in a stove at $70 \pm 2^{\circ} \mathrm{C}$, while the log samples and branches, were dried at $103 \pm 2^{\circ} \mathrm{C}$ (until constant weight) for determining the water content and estimating the dry matter. After the drying process the biomass samples were finely ground. Sub-samples of these were taken for later chemical analysis. Subsamples of biomass tree-components were subjected to wet digestion with sulphuric acid (Houba et al., 1986) subsequently followed by colorimetric method measurements of $\mathrm{N}$ and $\mathrm{P}$ concentration using a segmented flow autoanalyzer (SanPlus, Skalar, Breda, The Netherlands). For the $\mathrm{K}, \mathrm{Ca}, \mathrm{Mg}$ and $\mathrm{S}$ determinations, samples were digested with nitric-perchloric acid (Mills and Jones, 1996) and B by dry ash (Miller, 1998). $\mathrm{Ca}$ and Mg were determined by atomic absorption spectrophotometry (AAS 3100, PerkinElmer, USA), K by flame photometry (flame photometer PFP7, Jenway, UK) and S by the turbidimetric method (Coutinho, 1996). Total organic C was determined with a PRIMAC-SC carbon analyzer (Skalar, Breda, The Netherlands). Residual ash was determined by incineration at $450^{\circ} \mathrm{C}$ for $6 \mathrm{~h}$ in a muffle furnace.

Dataset used in mineralomass modelling was characterized in Table 1 and biometric variables of 34 sampled trees in Table 2. 
Table 1. Mean value and respective standard deviation (in brackets) of the mineralomass $(n=34$ trees) for the minerals considered in the analysis.

\begin{tabular}{lccccc}
\hline Mineral & $\begin{array}{c}\text { M_Wood } \\
(\mathbf{k g})\end{array}$ & $\begin{array}{c}\text { M_Bark } \\
(\mathbf{k g})\end{array}$ & $\begin{array}{c}\text { M_Bliv } \\
(\mathbf{k g})\end{array}$ & $\begin{array}{c}\text { M_Ltot } \\
\mathbf{( k g )}\end{array}$ & $\begin{array}{c}\text { M_Tot } \\
(\mathbf{k g})\end{array}$ \\
\hline $\mathrm{N}$ & 0.489 & 0.203 & 0.379 & 0.225 & 1.451 \\
& $(0.572)$ & $(0.155)$ & $(0.476)$ & $(0.199)$ & $(1.489)$ \\
$\mathrm{P}$ & 0.047 & 0.017 & 0.048 & 0.015 & 0.140 \\
& $(0.062)$ & $(0.015)$ & $(0.062)$ & $(0.011)$ & $(0.151)$ \\
$\mathrm{K}$ & 0.105 & 0.085 & 0.201 & 0.074 & 0.500 \\
& $(0.161)$ & $(0.085)$ & $(0.205)$ & $(0.065)$ & $(0.427)$ \\
$\mathrm{Ca}$ & 0.307 & 0.594 & 0.394 & 0.036 & 1.448 \\
& $(0.414)$ & $(0.436)$ & $(0.389)$ & $(0.028)$ & $(1.143)$ \\
$\mathrm{Mg}$ & 0.107 & 0.065 & 0.129 & 0.037 & 0.379 \\
& $(0.114)$ & $(0.047)$ & $(0.166)$ & $(0.030)$ & $(0.379)$ \\
$\mathrm{S}$ & 0.059 & 0.008 & 0.016 & 0.010 & 0.097 \\
& $(0.081)$ & $(0.008)$ & $(0.019)$ & $(0.008)$ & $(0.106)$ \\
$\mathrm{B} 1$ & 0.977 & 0.461 & 0.904 & 0.116 & 2.703 \\
& $(1.966)$ & $(0.360)$ & $(1.084)$ & $(0.100)$ & $(2.623)$ \\
$\mathrm{C}$ & 226.714 & 26.034 & 73.731 & 5.289 & 354.902 \\
& $(179.350)$ & $(18.832)$ & $(92.717)$ & $(4.446)$ & $(310.320)$ \\
\hline
\end{tabular}

${ }^{1}$ Mineralomass of $B$ in g; M_Wood, mineralomass of main stem under bark; M_Bark, mineralomass of stem bark; M_Bliv, mineralomass of living branches; M_Ltot, mineralomass of leaves and flowers; M_Tot, the total above-ground mineralomass.

Table 2. Biometric variables of the 34 sampled trees.

\begin{tabular}{lcccc}
\hline Variable $^{1}$ & Minimum & Mean & Maximum & Stand. deviation \\
\hline DBH $(\mathrm{cm})$ & 10.25 & 33.98 & 64.20 & 14.14 \\
$h(\mathrm{~m})$ & 11.55 & 21.91 & 30.40 & 4.63 \\
\hline
\end{tabular}

${ }^{1} \mathrm{DBH}$, diameter breast height; $h$, total height.

\section{Data analysis}

To model the mineralomass (M) by tree-components, the following candidate allometric equations were tested, where $d$ represent the DBH and $h$ the total height of the tree:

(1) $\quad M=\beta_{0}+\beta_{1} d^{2} h$

(1.1) $M=\beta_{1} d^{2} h$

(2) $M=\beta_{0}+\beta_{1} d+\beta_{2} d^{2}$

(2.2) $\mathrm{M}=\beta_{1} d+\beta_{2} d^{2}$

(3) $\mathrm{M}=\beta_{1} d^{2}$

(4) $M=\beta_{1} d+\beta_{2} h$

(5) $M=\beta_{1}\left(d^{2} h\right)^{\beta 2}$

(6) $\quad M=\beta_{1} d^{\beta 2}$

Other equations, namely that used to fit biomass equations for chestnut high-forest (Patrício et al., 2005) were tested but they were eliminated because no significant parameters were found.

The same data used to develop biomass equations for sweet chestnut (Patrício et al., 2005) were on the base of this study. Thus, the following mineralomass of tree components: bark (M_Bark), leaves and flowers (M_Ltot), living branches (M_Bliv), main stem under bark (M_Wood), main stem over bark (M_Stem) and the total above-ground mineralomass (M_Tot), were considered for analytical purposes.

The mineralomass equations were fitted by the ordinary least squares method (OLS) associated with both the PROC REG (linear models) and PROC NLIN (non-linear models) 
procedures of SAS/STAT. The modified Gauss-Newton iterative method was applied in the non-linear model fitting.

To consider the logical constraint between the sum of the predicted mineralomass for tree components and the prediction for the total tree, a system of additive equations was used. A system of additive equations provides more accurate biomass (mineralomass) estimates than the common approach of separately fitting total tree and component biomass (mineralomass) equations using log transformed data through least squares regression (Bi et al., 2004). A simultaneous fit by SUR method using iterative seemingly unrelated regression (ITSUR) by PROC MODEL procedure of SAS/STAT was used for the final selected models.

The models were evaluated in terms of measures of fit and prediction ability: modelling efficiency (EM), mean square error (MSE), models parameter significance, $R^{2}$ of prediction ( $\mathrm{R}^{2}$ pred), mean of PRESS residuals (m_PRESS), and mean of the absolute values of the PRESS residuals (ma_PRESS) as well as the percentiles 95\% (P95) and 5\% (P5) of the PRESS residuals. The normality of the studentized residuals was analyzed using normal QQplots. The presence of heteroscedasticity associated with the error term of the models was checked by plotting the studentized residuals against the predicted values.

The regression assumptions departure was solved with non-linear iteratively reweighted least squares (IRWLS) using the Huber function with the maximum value of $r=1$ and weighting factors. The procedure was repeated for each mineral.

\section{RESULTS AND DISCUSSION}

The models 1 to 6 were fitted to the mineralomass data as described in the methodology. Given the high number of equations tested, we only present the selected equations with all significant parameters, after weighting. Table 3 presents fitting, precision and bias statistics for the selected models. The plot analysis of the studentized residuals was also taken into consideration in model selection.

The analysis accomplished, based on the criteria previously mentioned, led to the selection of the following equations for each tree component (Table 4).

The final models were simultaneously fitted by SUR method with the ITSUR procedure. Next, we present the final models for each mineral (Table 5). We also present the modeling efficiency (EM) of the equations, a measure similar to the adjusted $\mathrm{R}^{2}$ in linear models. The EM obtained by SUR method is generally lower than that obtained by OLS, but with a smaller standard error of the coefficients and with the guarantee of the additivity of the mineralomass of the tree components to obtain the total mineralomass of the tree.

These equations predicted the mineralomass of the tree components in $\mathrm{kg}$, based on the diameter at $1.30 \mathrm{~m}(d)$, with bark, except for the wood, in $\mathrm{cm}$ and the total height $(h)$ in $\mathrm{m}$. The mineralomass of boron is estimated in $\mathrm{g}$. 
Table 3. Fitting and prediction statistics of the models with the best performance for the mineralomass by tree component and by mineral, after weighing.

\begin{tabular}{|c|c|c|c|c|c|c|c|c|c|}
\hline Min. & Model & Comp. & MSE & EM & mPRESS & maPRESS & $\mathbf{R}_{\text {pred }}$ & P95 & P5 \\
\hline \multirow[t]{6}{*}{$\mathrm{N}$} & $(1.1)$ & M_Bark & $0.50710^{-7}$ & 0.957 & -0.003 & 0.033 & 0.862 & 0.065 & -0.101 \\
\hline & (3) & M_Ltot & $0.71810^{-5}$ & 0.837 & 0.007 & 0.076 & 0.715 & 0.264 & -0.163 \\
\hline & (3) & M_Bliv & $0.235710^{-4}$ & 0.767 & 0.043 & 0.181 & 0.477 & 0.832 & -0.260 \\
\hline & (3) & M_Wood & $0.28410^{-4}$ & 0.830 & 0.054 & 0.180 & 0.417 & 0.530 & -0.286 \\
\hline & (3) & M_Stem & $0.25710^{-3}$ & 0.944 & 0.096 & 0.611 & 0.803 & 2.853 & -1.168 \\
\hline & (1.1) & M_Tot & $0.53610^{-5}$ & 0.900 & 0.083 & 0.431 & 0.720 & 1.929 & -0.829 \\
\hline \multirow[t]{6}{*}{$P$} & (3) & M_Bark & $0.21610^{-7}$ & 0.895 & $0.52210^{-3}$ & 0.005 & 0.632 & 0.016 & -0.010 \\
\hline & (3) & M_Ltot & $0.37210^{-7}$ & 0.831 & $0.66510^{-3}$ & 0.005 & 0.672 & 0.015 & -0.008 \\
\hline & (3) & M_Bliv & $0.60810^{-7}$ & 0.660 & 0.006 & 0.027 & 0.309 & 0.102 & -0.040 \\
\hline & (3) & M_Wood & $0.82510^{-6}$ & 0.600 & 0.004 & 0.036 & 0.174 & 0.133 & -0.097 \\
\hline & (3) & M_Stem & $0.46610^{-5}$ & 0.882 & 0.004 & 0.081 & 0.634 & 0.211 & -0.193 \\
\hline & (3) & M_Tot & 0.005 & 0.803 & 0.008 & 0.066 & 0.509 & 0.327 & -0.145 \\
\hline \multirow[t]{6}{*}{$\mathrm{K}$} & (1.1) & M_Bark & $0.35010^{-7}$ & 0.822 & 0.005 & 0.031 & 0.578 & 0.099 & -0.049 \\
\hline & (3) & M_Ltot & $0.14410^{-5}$ & 0.763 & 0.004 & 0.033 & 0.633 & 0.081 & -0.056 \\
\hline & (3) & M_Bliv & $0.78610^{-5}$ & 0.752 & 0.016 & 0.096 & 0.524 & 0.274 & -0.135 \\
\hline & (1.1) & M_Wood & $0.15610^{-3}$ & 0.428 & 0.025 & 0.078 & 0.088 & 0.192 & -0.143 \\
\hline & (1.1) & M_Stem & 0.002 & 0.868 & 0.034 & 0.393 & 0.618 & 1.034 & -0.753 \\
\hline & (3) & M_Tot & 0.036 & 0.925 & 0.023 & 0.171 & 0.719 & 0.398 & -0.274 \\
\hline \multirow[t]{6}{*}{$\mathrm{Ca}$} & (3) & M_Bark & $0.39210^{-4}$ & 0.852 & -0.009 & 0.224 & 0.242 & 0.580 & -0.629 \\
\hline & (3) & M_Ltot & $0.33710^{-6}$ & 0.749 & 0.002 & 0.016 & 0.451 & 0.049 & -0.021 \\
\hline & (3) & M_Bliv & $0.35910^{-4}$ & 0.707 & 0.027 & 0.198 & 0.401 & 0.631 & -0.492 \\
\hline & (1.1) & M_Wood & $0.35210^{-3}$ & 0.773 & 0.023 & 0.148 & 0.538 & 0.673 & -0.258 \\
\hline & (1.1) & M_Stem & 0.088 & 0.891 & 0.119 & 2.260 & 0.498 & 5.256 & -6.362 \\
\hline & (1) & M_Tot & $0.41410^{-5}$ & 0.882 & 0.020 & 0.286 & 0.870 & 0.687 & -0.565 \\
\hline \multirow[t]{6}{*}{$\mathrm{Mg}$} & (3) & M_Bark & $0.75210^{-6}$ & 0.779 & $0.40810^{-3}$ & 0.024 & 0.357 & 0.064 & -0.048 \\
\hline & (3) & M_Ltot & $0.22910^{-6}$ & 0.822 & 0.002 & 0.014 & 0.719 & 0.040 & -0.022 \\
\hline & (3) & M_Bliv & $0,28310^{-5}$ & 0.759 & 0.016 & 0.059 & 0.465 & 0.232 & -0.083 \\
\hline & (1.1) & M_Wood & $0.22910^{-4}$ & 0.874 & 0.006 & 0.037 & 0.681 & 0.151 & -0.071 \\
\hline & (3) & M_Stem & 0.001 & 0.893 & 0.025 & 0.243 & 0.637 & 0.845 & -0.540 \\
\hline & (1) & M_Tot & $0.47910^{-6}$ & 0.818 & 0.023 & 0.125 & 0.642 & 0.326 & -0.203 \\
\hline \multirow[t]{6}{*}{$S$} & (1.1) & M_Bark & $0.32110^{-9}$ & 0.835 & $0.12810^{-4}$ & 0.003 & 0.510 & 0.010 & -0.009 \\
\hline & (3) & M_Ltot & $0.15510^{-7}$ & 0.852 & $0.14310^{-3}$ & 0.003 & 0.692 & 0.009 & -0.009 \\
\hline & (3) & M_Bliv & $0.35110^{-7}$ & 0.797 & 0.001 & 0.007 & 0.619 & 0.036 & -0.010 \\
\hline & (1.1) & M_Wood & $0.26010^{-4}$ & 0.616 & 0.008 & 0.036 & 0.314 & 0.183 & 0.054 \\
\hline & (1.1) & M_Stem & $0.95610^{-4}$ & 0.775 & 0.008 & 0.074 & 0.461 & 0.239 & -0.126 \\
\hline & (1.1) & M_Tot & $0.39710^{-7}$ & 0.827 & 0.008 & 0.034 & 0.631 & 0.159 & -0.060 \\
\hline \multirow[t]{6}{*}{$\mathrm{B}^{1}$} & (3) & M_Bark & $0.11910^{-4}$ & 0.915 & 0.004 & 0.129 & 0.780 & 0.273 & -0.292 \\
\hline & (3) & M_Ltot & $0.49110^{-5}$ & 0.684 & 0.001 & 0.055 & 0.507 & 0.236 & -0.090 \\
\hline & (3) & M_Bliv & $0.12510^{-3}$ & 0.786 & 0.088 & 0.397 & 0.562 & 1.154 & -0.513 \\
\hline & (3) & M_Wood & $0.15010^{-3}$ & 0.806 & 0.011 & 0.407 & 0.576 & 0.997 & -1.191 \\
\hline & (3) & M_Stem & $0.16810^{-3}$ & 0.927 & 0.083 & 1.475 & 0.822 & 4.063 & -3.473 \\
\hline & (1.1) & M_Tot & $0.23710^{-4}$ & 0.915 & -0.006 & 0.831 & 0.819 & 2.335 & -2.487 \\
\hline \multirow[t]{6}{*}{ C } & (5) & M_Bark & $0.43710^{-3}$ & 0.963 & 0.071 & 3.074 & 0.950 & 8.348 & -7.686 \\
\hline & (3) & M_Ltot & 0.004 & 0.838 & 0.152 & 1.976 & 0.712 & 5.862 & -3.541 \\
\hline & (3) & M_Bliv & 0.887 & 0.757 & 8.031 & 35.97 & 0.560 & 188.41 & -52.166 \\
\hline & (5) & M_Wood & 0.012 & 0.978 & -1.141 & 26.027 & 0.933 & 64.273 & -40.100 \\
\hline & (5) & M_Stem & 0.090 & 0.982 & -3.611 & 52.653 & 0.946 & 156.17 & -103.88 \\
\hline & (6) & M_Tot & 0.860 & 0.984 & -0.942 & 34.370 & 0.972 & 66.810 & -107.67 \\
\hline
\end{tabular}

${ }^{1}$ Mineralomass of $B$ in $\mathrm{g}$; Mineralomass of the remaining minerals in $\mathrm{kg}$. MSE, mean square error; EM, modelling efficiency; m_PRESS, mean of PRESS residuals; ma_PRESS, mean of the absolute values of the PRESS residuals; $R^{2}$ pred, $R^{2}$ of prediction; P95 and P5, percentiles $95 \%$ and $5 \%$ of the PRESS residuals. 
Table 4. Equation for each mineral (nitrogen, phosphorus, potassium, calcium, magnesium, sulfur, boron, carbon), subdivided by tree component.

\begin{tabular}{lll}
\hline Nitrogen & Phosphorus & Potassium \\
\hline N_Bark $=0.626010^{-5} d^{2} h$ & P_Bark $=0.125010^{-4} d^{2}$ & K_Bark $=0.240010^{-5} d^{2} h$ \\
N_Ltot $=0.176810^{-3} d^{2}$ & P_Ltot $=0.123010^{-4} d^{2}$ & K_Ltot $=0.622010^{-4} d^{2}$ \\
N_Bliv $=0.250510^{-3} d^{2}$ & P_Bliv $=0.307010^{-4} d^{2}$ & K_Bliv $=0.137010^{-3} d^{2}$ \\
N_Wood $=0.323210^{-3} d^{2}$ & P_Wood $=0.321710^{-4} d^{2}$ & K_Wood $=0.243010^{-5} d^{2 h}$ \\
N_Stem $=0.00193 d^{2}$ & P_Stem $=0.171310^{-3} d^{2}$ & K_Stem $=0.303610^{-4} d^{2} h$ \\
N_Tot $=0.413810^{-4} d^{2} h$ & P_Total $=0.103010^{-3} d^{2}$ & K_Total $=0.406010^{-3} d^{2}$ \\
\hline Calcium & Magnesium & Sulfur \\
Ca_Bark $=0.415210^{-3} d^{2}$ & Mg_Bark $=0.475010^{-4} d^{2}$ & S_Bark $=0.246610^{-6} d^{2} h$ \\
Ca_Ltot $=0.282410^{-4} d^{2}$ & Mg_Ltot $=0.299110^{-4} d^{2}$ & S_Ltot $=0.752010^{-5} d^{2}$ \\
Ca_Bliv $=0.267110^{-3} d^{2}$ & Mg_Bliv $=0.838310^{-4} d^{2}$ & S_Bliv $=0.106310^{-4} d^{2}$ \\
Ca_Wood $=0.8670100^{-5} d^{2} h$ & Mg_Wood $=0.308010^{-5} d^{2} h$ & S_Wood $=0.155010^{-5} d^{2} h$ \\
Ca_Stem $=0.204110^{-3} d^{2} h$ & Mg_Stem $=0.232510^{-4} d^{2} h$ & S_Stem $=0.442010^{-5} d^{2} h$ \\
Ca_Total $=0.1062+0.377710^{-4} d^{2} h$ & Mg_Total $=0.0336+0.995010^{-5} d^{2} h$ & S_Total $=0.258010^{-5} d^{2} h$ \\
\hline Boron & Carbon & \\
B_Bark $=0.338610^{-3} d^{2}$ & C_Bark $=0.0076\left(d^{2} h\right)^{0.7880}$ & \\
B_Ltot $=0.934010^{-4} d^{2}$ & C_Ltot $=0.0045 d^{2}$ & \\
B_Bliv $=0.607010^{-3} d^{2}$ & C_Bliv $=0.0490 d^{2}$ & \\
B_Wood $=0.716010^{-3} d^{2}$ & C_Wood $=0.0138\left(d^{2} h\right)^{0.9360}$ & \\
B_Stem $=0.00438 d^{2}$ & C_Stem $=0.0342\left(d^{2} h\right)^{0.9299}$ & \\
B_Total $=0.943710^{-4} d^{2} h$ & C_Total $=0.0630 d^{2.3754}$ & \\
\hline
\end{tabular}

_Bark, equation for stem bark; _Ltot, equation for leaves and flowers; _Bliv, equation for living branches; _Wood, equation for main stem under bark; _Stem, equation for main stem over bark; _Total, equation for total above-ground.

Table 5. Final equation model and modeling efficiency (EM) for each mineral (nitrogen, phosphorus, potassium, calcium, magnesium, sulfur, boron, carbon).

\begin{tabular}{lllllc}
\hline Mineral & Equation & EM & Mineral & Equation & EM \\
\hline Nitrogen & N_Bark $=0.587710^{-5} d^{2} h$ & 0.8871 & Magnesium & Mg_Bark $=0.430010^{-4} d^{2}$ & 0.4369 \\
& N_Ltot $=0.170010^{-3} d^{2}$ & 0.7266 & & Mg_Ltot $=0.300010^{-4} d^{2}$ & 0.7398 \\
& N_Bliv $=0.293010^{-3} d^{2}$ & 0.5437 & & Mg_Bliv $=0.970010^{-4} d^{2}$ & 0.5323 \\
& N_Wood $=0.366010^{-3} d^{2}$ & 0.4609 & & Mg_Wood $=0.310010^{-5} d^{2} h$ & 0.7125 \\
& N_Total & 0.7209 & & Mg_Total & 0.7246 \\
\hline Phosphorus & P_Bark $=0.140010^{-4} d^{2}$ & 0.6318 & Sulfur & S_Bark $=0.244110^{-6} d^{2} h$ & 0.5537 \\
& P_Ltot $=0.120010^{-4} d^{2}$ & 0.6954 & & S_Ltot $=0.738810^{-5} d^{2}$ & 0.7147 \\
& P_Bliv $=0.340010^{-4} d^{2}$ & 0.3639 & & S_Bliv $=0.110010^{-4} d^{2}$ & 0.6622 \\
& P_Wood $=0.380010^{-4} d^{2}$ & 0.2128 & & S_Wood $=0.187210^{-5} d^{2 h}$ & 0.3827 \\
& P_Total & 0.4951 & & S_Total & 0.5925 \\
\hline Potassium & K_Bark $=0.281210^{-5} d^{2} h$ & 0.5853 & Boron & B_Bark $=0.333010^{-3} d^{2}$ & 0.8000 \\
& K_Ltot $=0.660010^{-4} d^{2}$ & 0.6634 & & B_Ltot $=0.920010^{-4} d^{2}$ & 0.5354 \\
& K_Bliv $=0.148010^{-3} d^{2}$ & 0.5638 & & B_Bliv $=0.65510^{-3} d^{2}$ & 0.6128 \\
& K_Wood $=0.710010^{-4} d^{2}$ & 0.0932 & & B_Wood $=0.794010^{-3} d^{2}$ & 0.6011 \\
& K_Total & 0.7427 & & B_Total & 0.7830 \\
\hline Calcium & Ca_Bark $=0.473010^{-3} d^{2}$ & 0.2546 & Carbon & C_Bark $=0.010008\left(d^{2} h\right)^{0.760258}$ & 0.9491 \\
& Ca_Ltot $=0.260010^{-4} d^{2}$ & 0.4772 & & C_Ltot $=0.004172 d^{2}$ & 0.7175 \\
& Ca_Bliv $=0.249110^{-3} d^{2}$ & 0.4221 & & C_Bliv $=0.041554 d^{2}$ & 0.5124 \\
& Ca_Wood $=0.879610^{-5} d^{2} h$ & 0.5882 & & C_Wood $=0.010784\left(d^{2} h\right)^{0.960756}$ & 0.9314 \\
& Ca_Total & 0.7998 & & C_Total & 0.9103 \\
\hline
\end{tabular}

_Bark, equation for stem bark; _Ltot, equation for leaves and flowers; _Bliv, equation for living branches; _Wood, equation for main stem under bark; _Total, equation for total above-ground. 


\section{CONCLUSIONS}

At the end of this study two types of mineralomass equations for high-forest chestnut management were provided: 48 total tree and tree component equations, separately fitted, and 8 systems of additive mineralomass equations, both for $\mathrm{N}, \mathrm{P}, \mathrm{K}, \mathrm{Ca}, \mathrm{Mg}, \mathrm{S}, \mathrm{B}$ and $\mathrm{C}$. This kind of equations is very useful for forestry management purposes. These mineralomass equations, applicable to data of individual trees of forest inventories, are useful for assessing the impact of a wide variety of ecological problems on ecosystems, like forest fires, carbon sequestration, harvesting effects and forestry management on nutrient balance and site sustainability.

\section{ACKNOWLEDGEMENTS}

This work was supported by the AGRO Program, Project 267: Sustainable Management of Chestnut Woodlands in High-forest and Coppice Systems.

\section{Literature cited}

Augusto, L., Ranger, J., Ponette, Q., and Rapp, M. (2000). Relationships between forest tree species, stand production and stand nutrient amount. Ann. For. Sci. 57 (4), 313-324 https://doi.org/10.1051/forest:2000122.

Bi, H., Turner, J., and Lambert, M.J. (2004). Additive biomass equations for native eucalypt forest trees of temperate Australia. Trees (Berl.) 18 (4), 467-479 https://doi.org/10.1007/s00468-004-0333-z.

Coutinho, J. (1996). Automated method for sulphate determination in soil-plant extracts and waters. Com. Soil Sci. Plant Anal. 27 (3-4), 727-740 https://doi.org/10.1080/00103629609369590.

Houba, V.J.G., Van Der Lee, J.J., Novozamski, I., and Walinga, I. (1986). Soil and Plant Analysis Procedures (Wageningen: Wageningen University), pp.262.

Miller, R.O. (1998). High-temperature oxidation: dry ashing. In Handbook and Reference Methods for Plant Analysis, Y.P. Kalra, ed. (Boca Raton, Florida: CRC Press), p.53-56.

Mills, H.A., and Jones, J.B., Jr. (1996). Plant Analysis Handbook II (Athens, Georgia, USA: MicroMacro Publishing, Inc.), pp.422.

Patrício, M.S., Monteiro, M.L., and Tomé, M. (2005). Biomass equations for Castanea sativa high-forest in the Northwest of Portugal. Acta Hortic. 693, 727-732 https://doi.org/10.17660/ActaHortic.2005.693.98.

Patrício, M.S., Pereira, E., Nunes, L.F., and Monteiro, M.L. (2009). Carbon and nutrient inputs by litterfall into three chestnut high forest stands in northern Portugal. Acta Hortic. 815, 69-74 https://doi.org/10.17660/ActaHortic. 2009.815.9.

Patrício, M.S., Nunes, L.F., and Pereira, E.L. (2012). Litterfall and litter decomposition in chestnut high forest stands in northern Portugal. For. Syst. 21 (2), 259-271 https://doi.org/10.5424/fs/2012212-02711.

Patrício, M.S., Nunes, L.F., and Pereira, E.L. (2014). Evaluation of soil organic carbon storage in a sustainable forest chestnut context. Acta Hortic. 1043, 161-165 https://doi.org/10.17660/ActaHortic.2014.1043.21. 
